\title{
Risk Factors for the Presence of Mycobacterium avium spp. paratuberculosis in Human Intestinal Biopsies in Brazil
}

Espeschit IF ${ }^{1}$, Carvalho IA ${ }^{1}$, Oliveira J F', Souza MCC ${ }^{1}$, Valêncio $A^{2}$, Ferrari MLA $^{3}$ and Moreira MAS $^{1 *}$

'Bacterial Diseases Laboratory, Section of Preventive Veterinary Medicine and Public Health, Universidade Federal de Viçosa- UFV, Brazil

${ }^{2}$ Department of Economics, Universidade Federal de Viçosa-UFV, Brazil

${ }^{3}$ Alpha Institute of Gastroenterology, Universidade Federal de Minas Gerais-UFMG, Brazil

*Corresponding author: Moreira MAS, Bacterial Diseases Laboratory, Section of Preventive Veterinary Medicine and Public Health. Universidade Federal de Viçosa- UFV. PH Rolfs Avenue, Campus Universitary, Zip Code 36570-900. Vicosa, Minas Gerais state, Brazil

Received: May 05, 2017; Accepted: June 02, 2017; Published: J une 19, 2017

\begin{abstract}
Mycobacterium avium subsp. paratuberculosis (MAP) is the etiologic agent of Johne's disease or paratuberculosis, a persistent gastroenteritis that affects ruminants and leads to progressive weight loss. In humans, MAP has been frequently isolated from patients with Crohn's disease (CD), the etiology of which is still unclear. Although paratuberculosis and $C D$ have many clinical and histological similarities, the role of MAP in CD pathogenesis is unknown. Therefore, due to its zoonotic potential, it is important to detect factors that can favor MAP infection in humans. A case-control study was carried out in a population of patients who underwent a colonoscopy between 2009 and 2011 at a gastroenterology referral center, located in the Hospital das Clinicas, Universidade Federal de Minas Gerais (HC-UFMG), Belo Horizonte-MG. Eight out of a total of 148 patients had a positive intestinal biopsy for the presence of MAP DNA. In the risk factor analysis, MAP was positively associated with the consumption of unpasteurized dairy products (Odds ratio=13.39, $\mathrm{Cl}=1.57$ to 298; $\mathrm{p}<0.01$ ) and a history of intestinal diseases among family members (odds $=8.42$; IC=1.44 to $63.50 ; P<0.01$ ). This study suggests that consumption of informally marketed milk and a history of intestinal diseases among family members are risk factors for the occurrence of MAP in intestinal biopsy samples. These data reinforce what has been described in studies in other countries. This is the first report on the subject in Brazil.
\end{abstract}

Keywords: Crohn's disease; Milk; Case-control; Inflammatory bowel disease

\section{Introduction}

Mycobacterium avium subsp. paratuberculosis (MAP), a Grampositive bacillus, is the etiologic agent of chronic granulomatous inflammatory bowel disease, known as paratuberculosis or Johne's disease. Paratuberculosis is usually a subclinical disease that may progress to the clinical form in adult animals. It can affect domestic and wild ruminants and pseudoruminants $[1,2]$.

This bacterium has been isolated from patients with inflammatory bowel disease (IBD), mostly Crohn's disease (CD) and less frequently in patients with ulcerative colitis (UC). CD is an inflammatory bowel disease of unknown etiology characterized by chronic inflammation and focal, transmural and granulomatous asymmetry that may affect any part of the digestive tract, from the mouth to the anus, but is mainly found in the distal small intestine and proximal large intestine [3].

As described by Robertson, et al. (2017) the relation of MAP and $\mathrm{CD}$ still controversial and hotly discussed, but with the modernization of molecular techniques, the DNA of MAP has been detected in tissue samples obtained from patients with $\mathrm{CD}$ at increasing rates, including patients with IBD and other noninflammatory bowel diseases, such as intestinal cancer, hemorroidal disease [4-6]. The frequent isolation of MAP in intestinal specimens from patients with $\mathrm{CD}$ and clinical, histological and radiological similarities, between paratuberculosis and CD, raises concerns about the zoonotic potential of MAP [7-9]. The agent is eliminated in the feces and milk of infected animals, which may contaminate food and water courses, thus exposing communities to the agent. Also, MAP is resistant to high temperatures and disinfectants, so it can be present in pasteurized dairy products and drinking water, as demonstrated by previous studies. Pasteurization can decrease the bacterial load without eliminating it from dairy products. The same is true for drinking water and wastewater treatment [9-14].

According to Uzoigweet, et al. (2007), research into the risk factors of $\mathrm{CD}$ has been frustrating. However, epidemiologists have gathered enough information that points to an association between M. avium subsp. paratuberculosis and CD [15]. A study performed by Scanu, et al. (2007) in the United Kingdom supplied data on the potential risk factors for human exposure to some pathogens; these authors found that MAP is a candidate pathogen of cases of IBD and CD, and there was a significant association between MAP infection and the consumption of handmade cheese in CD patients [16]. Zamani, et al. (2017) also found high immune reactivity to MAP epitopes among $\mathrm{CD}$ patients, which was positively correlated with the consumption of fast food meals and a family history of IBD. For both $\mathrm{CD}$ and $\mathrm{UC}$, the duration of breastfeeding and the consumption of fruit/vegetables had a negative correlation with the presence of antiMAP antibodies in Iranian CD patients [17]. Abubakar, et al. (2006)
Austin J Gastroenterol - Volume 4 Issue 2 - 2017

ISSN : 2381-9219 | www.austinpublishing group.com

Moreira et al. () All rights are reserved
Citation: Espeschit IF, Carvalho IA, Oliveira JF, Souza MCC, Valêncio A, Ferrari MLA, et al. Risk Factors for the Presence of Mycobacterium avium spp. paratuberculosis in Human Intestinal Biopsies in Brazil. Austin J Gastroenterol. 2017; 4(2): 1083. 
also reported a risk factor study for MAP in the United Kingdom, where they found that the consumption of pasteurized milk was associated with a reduced risk of CD. Meat intake was associated with a significantly increased risk of $\mathrm{CD}$, whereas fruit consumption was associated with a reduced risk [18]. Dow, et al. (2006) and Pinna, et al. (2014) reported that MAP infection may also be a risk factor for other diseases, such as diabetes $[19,20]$.

Although there have been risk factors studies performed in other countries, in Brazil, there have been no previous reports of this kind, even though there are important centers for the treatment of $\mathrm{CD}$ in the country. Thus, the present study aimed to find possible risk factors for the presence MAP in samples of human intestinal biopsies collected from patients of a reference center of $\mathrm{CD}$ of Brazil.

\section{Material and Methods}

\section{Samples and study design}

The present study was conducted at the referral center Alpha Institute of Gastroenterology located at the Clinics Hospital of Universidade Federal de Minas Gerais (HC-UFMG). As a referral center for the area, it receives patients from different regions of Minas Gerais state. The patients had bowel fragments collected for biopsy between 2009 and 2011.

This study constitutes a continuation of a previous one, described by Carvalho, et al. (2015), in which the aim was to verify if there was difference in the detection and quantification of MAP DNA in intestinal samples from patients with IBD, mainly $\mathrm{CD}$, and patients without IBD, which underwent colonoscopy between the years 2009 and 2011 by real-time PCR [6]. The present study analysed the same population, studying the risk factors that could be influencing the occurrence of MAP, identified in the previous study, in these samples, independently of the diagnosis (IBD or non-IBD).

Therefore, data collection for the case-control study was conducted from 2013 to 2015 at the same reference institute and with the same population [6]. Patients who had positive biopsies for MAP DNA in the previous study were considered cases. The controls were considered the remaining sampled individuals, who presented a negative biopsy for the presence of MAP DNA.

\section{Data collection}

The personal and medical information of the patients was collected from the records of the Medical Archive and Statistics Service (SAME) of HC/UFMG. The patients were contacted either or by telephone, or during their visit to the institute for consultation or any medical procedure.

A standard pre-coded questionnaire was the data collection tool used to identify the condition of patients and control participants regarding the exposure to the analyzed variables. The final version of the questionnaire was organized through the following sections: informed consent, participant identifications, information about the disease, family history of disease, socioeconomic characteristics, household characteristics and consumption of dairy products.

The questionnaire was answered by the patient and applied by a single interviewer, who did not know the status (case or control) of the patient at the time of the interview, aiming to prevent interviewer bias. All questions were related to the period prior to the performance of the biopsy. Although interviewer bias was minimized, the search results were subject to recall bias, since the individuals were asked about an earlier period of their lives.

\section{Data analysis}

The analysis of the case-control study data began with the construction of the database in the Epi Info software system version 3.5.3 (CDC, 2011) [21], into which the responses from each questionnaire were entered. The statistical analysis comprised univariate analysis followed by bivariate analysis. These analyses were performed with a equal to 5\%. All participants were informed about the objectives of the study and provided written informed consent before answering the questionnaire. The study was approved by the ethics committee of the Universidade Federal de Minas Gerais. (ETIC no0471.0.203.000-10).

\section{Results and Discussion}

We considered the cases of eight patients with intestinal biopsies showing MAP DNA; 148 patients were included in the study as controls and another 24 patients were excluded due to death or incomplete information. The proportion of cases and controls was 1 case for 17.5 controls. Although the number of patients included in the study is small, the information supplied for the studied population is novel, considering the studied country. There are no previous studies describing the specificities of CD in Brazil, or correlating with MAP infection. Also, because of the ethical barriers, it is not easy to work with the human population in our country.

The complete distribution of the variables can be found in the Tables 1 to 4 . Since the Alpha Institute is considered a referral center for IBD, most participants with intestinal problems were diagnosed with CD (38.5\%), followed by non-IBD patients (34.5\%) and patients with ulcerative colitis (UC) (25.6\%). Among the eight cases, the diagnosis indicated UC (37.5\%) and non-IBD patients (37.5\%), while $\mathrm{CD}$ was diagnosed in only $25 \%$ of the subjects. This distribution differs from that of controls, where $39.9 \%$ were diagnosed with CD, $25.4 \%$ were diagnosed with UC and $32.9 \%$ did not have IBD, as described in Table 3. This was expected, given the frequent isolation of the agent in patients with $\mathrm{CD}$, as previously discussed. Comparable results were found by Timms, et al (2016) that published a study reporting a significant association between MAP and CD that was not related to age, gender, and place of birth [22]

Comparing cases and controls, we found that clinical treatment was received by $87.5 \%$ of cases and $68.3 \%$ of controls. In relation to surgical treatment, only $12.5 \%$ of the cases did not need a surgical procedure, while $67.6 \%$ of controls did undergo surgery.

The univariate analysis demonstrated that there were a higher proportion of individuals who are homeowners among the controls. This distribution was expected, as individuals who are not homeowners are more likely to move more frequently, which exposes them to a greater diversity of pathogens, since they use new water sources and may be exposed to sewage that can be contaminated (Table 1).

Similarly, individuals who do not have access to a public supply of clean water or proper sewage disposal, and those that eat unpasteurized, non-inspected products had increased chances 
Table 1: Association between socioeconomic variables and intestinal biopsies MAP DNA detection amongst cases.

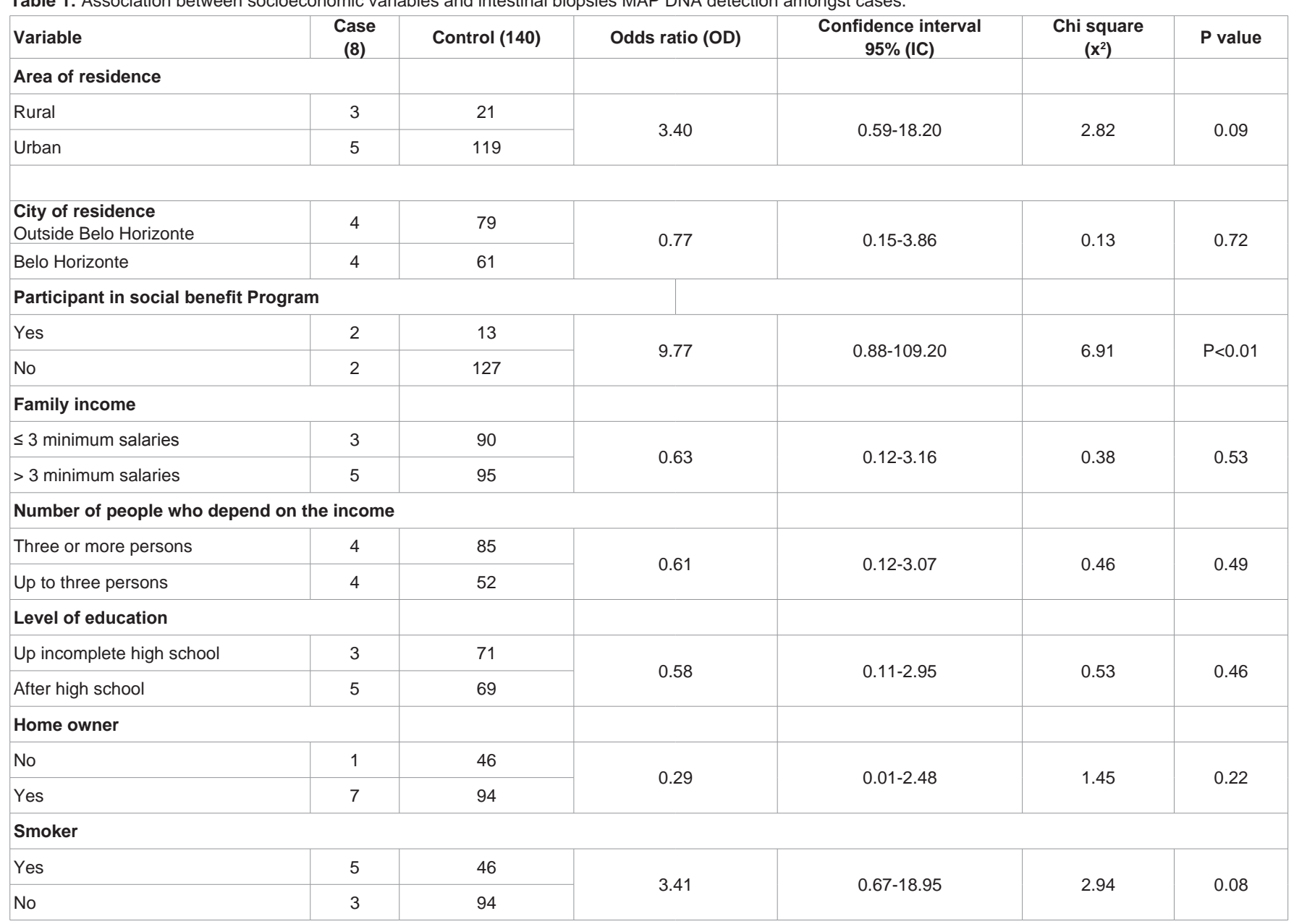

Table 2: Association between sanitation variables and intestinal biopsies MAP DNA detection amongst cases.

\begin{tabular}{|c|c|c|c|c|c|c|}
\hline Variable & $\begin{array}{l}\text { Case } \\
(8)\end{array}$ & Control (140) & Odds ratio (OD) & Confidence interval $95 \%$ (IC) & $\begin{array}{c}\text { Chi square } \\
\left(x^{2}\right)\end{array}$ & $P$ value \\
\hline \multicolumn{7}{|l|}{ Water supply source } \\
\hline Other source & 3 & 27 & \multirow{2}{*}{2.51} & \multirow{2}{*}{$0.44-13.16$} & \multirow{2}{*}{1.55} & \multirow{2}{*}{0.21} \\
\hline Public network system & 5 & 113 & & & & \\
\hline \multicolumn{7}{|c|}{ Performs treatment of water for consumption } \\
\hline No & 0 & 9 & \multirow{2}{*}{0.00} & \multirow{2}{*}{$0.00-11.73$} & \multirow{2}{*}{0.55} & \multirow{2}{*}{0.45} \\
\hline Yes & 8 & 131 & & & & \\
\hline \multicolumn{7}{|l|}{ Wastewater disposal } \\
\hline Other system & 3 & 24 & \multirow{2}{*}{2.88} & \multirow{2}{*}{$0.50-15.21$} & \multirow{2}{*}{2.07} & \multirow{2}{*}{0.15} \\
\hline Public collection system & 5 & 115 & & & & \\
\hline
\end{tabular}

of coming into contact with microbial agents, such as MAP. Also, regarding sanitation and socioeconomic conditions, the use of springs or wells increases the chances of contact with pathogens such as MAP, since the water receives no treatment prior to use. In addition, septic tanks may pose a risk to the health of users, if they are not used or built correctly. They could expose users to various pathogens, due to leaks and the contamination of soil and sources of water. This can be shown in our study, since there were a higher percentage of individuals under poor sanitary conditions among the cases as described in Table 2.

Among the controls, there were a higher proportion of nonsmokers, but there were also individuals who smoke a greater number of cigarettes (Table 1). It is known that smoking is associated with the occurrence of IBD and is a risk factor for CD. However, it works as a protective factor in patients with UC, and individuals with UC are at an increased risk of developing disease if they stop smoking [9]. Although the participation of MAP in the appearance of these inflammatory lesions has not been clarified, it can be inferred that 
Table 3: Association between information's treatment, family history and disease variables to intestinal biopsies MAP DNA detection amongst cases.

\begin{tabular}{|c|c|c|c|c|c|c|}
\hline Variable & $\begin{array}{c}\text { Case } \\
(8)\end{array}$ & Control (140) & $\begin{array}{l}\text { Odds ratio } \\
\text { (OD) }\end{array}$ & $\begin{array}{l}\text { Confidence interval } 95 \% \\
\text { (IC) }\end{array}$ & $\begin{array}{l}\text { Chi square } \\
\left(x^{2}\right)\end{array}$ & $P$ value \\
\hline \multicolumn{7}{|l|}{ Diagnostic } \\
\hline Crohn/Ulcerative colitis & 5 & 90 & \multirow{2}{*}{0.87} & \multirow{2}{*}{$0.17-4.84$} & \multirow{2}{*}{0.03} & \multirow{2}{*}{0.85} \\
\hline Others diseases & 3 & 47 & & & & \\
\hline \multicolumn{7}{|l|}{ Treatment and treatment habits } \\
\hline $\begin{array}{l}\text { Doctor's prescription associated with alternative therapies } \\
\text { and self-medication }\end{array}$ & 2 & 41 & \multirow{2}{*}{0.67} & \multirow{2}{*}{ 0.09-3.95 } & \multirow{2}{*}{0.22} & \multirow{2}{*}{0.63} \\
\hline Only Doctor's prescription & 6 & 83 & & & & \\
\hline \multicolumn{7}{|l|}{ Family history of bowel diseases } \\
\hline Yes & 6 & 36 & \multirow{2}{*}{8.42} & \multirow{2}{*}{$1.44-63.50$} & \multirow{2}{*}{8.72} & \multirow{2}{*}{$P<0.01$} \\
\hline No & 2 & 101 & & & & \\
\hline
\end{tabular}

Table 4: Association between information's consumption of dairy products and intestinal biopsies MAP DNA detection amongst cases.

\begin{tabular}{|c|c|c|c|c|c|c|}
\hline Variable & $\begin{array}{c}\text { Case } \\
(8)\end{array}$ & Control (140) & Odds ratio (OD) & Confidence interval $95 \%$ (IC) & $\begin{array}{c}\text { Chi square } \\
\left(x^{2}\right)\end{array}$ & $P$ value \\
\hline \multicolumn{7}{|l|}{ Frequency of consume dairy products } \\
\hline More than once per week & 7 & 75 & \multirow{2}{*}{5.97} & \multirow{2}{*}{$0.71-132.62$} & \multirow{2}{*}{3.45} & \multirow{2}{*}{0.06} \\
\hline Less than once per week and no consumption & 1 & 64 & & & & \\
\hline \multicolumn{7}{|c|}{ Drinks and/or eats informally marketed dairy products } \\
\hline Yes & 8 & 46 & \multirow{2}{*}{13.39} & \multirow{2}{*}{$1.57-298$} & \multirow{2}{*}{9.12} & \multirow{2}{*}{$P<0.01$} \\
\hline No & 1 & 88 & & & & \\
\hline \multicolumn{7}{|l|}{ Informal (raw) milk consumption } \\
\hline Yes & 5 & 12 & \multirow{2}{*}{4.72} & \multirow{2}{*}{$0.80-30.37$} & \multirow{2}{*}{4.19} & \multirow{2}{*}{0.04} \\
\hline No & 3 & 34 & & & & \\
\hline
\end{tabular}

risk factors occurring concomitantly may increase the chances of developing or even aggravating the disease.

Self-medication is not an advisable practice, especially in the case of patients with bacterial infections, which may be the case in MAP DNA detection, although its role in the pathogenesis of intestinal diseases has not been explained yet. The use of non-prescription drugs, such as antibiotics, may aggravate the symptoms, since inaccurate dosing can lead to bacterial resistance [23]. In the present study, this behavior was more common among cases than among controls (Table 3).

Drinking and eating dairy products is another variable possibly associated with the contamination of individuals with MAP, especially non-pasteurized products. However, it is known that pasteurization may not be able to remove high bacterial loads of an agent, and bacteria can be detected in pasteurized milk and products such as curd cheese $[14,24,25]$. Among the cases, $62.5 \%$ of the subjects consume raw products, while among controls, this percentage was $10.8 \%$. Thus, cases probably came into contact with MAP through the consumption of raw milk, as described by Carvalho, et al. (2012), who also identified the viable agent in pasteurized milk [14]. As expected, the purchase of these products from small businesses or informal vendors is more common among patients with positive MAP diagnosis in their biopsies, which indicates that the consumption of milk and other informally marketed dairy products is associated with MAP detection in the human intestine. This association was expected, since MAP is eliminated by contaminated animals, mainly through the milk and feces. Thus, individuals may be contaminated by consuming these products, especially non-pasteurized products, although pasteurization may not be able to remove high bacterial loads. This probably occurs due to the ability of bacteria to form clumps. The bacteria inside the clumps would be protected from the heat by those on the outer surface during pasteurization $[13,24]$. In addition to the formation of clumps, MAP also has the ability to form a spore-like structure that may hinder its elimination and favor bacterial survival in the environment, as observed in aquatic environments, since MAP has been identified in raw milk and untreated water $[11,13,26,27]$.

A history of intestinal diseases among family members, also described by other researchers including Nacy, et al. (2008), Fiocchi (2012), Leite (2012) and Carvalho, et al., (2012), was another factor showing a statistical association, which suggests the involvement of MAP in intestinal diseases, especially CD $[8,9,14,28]$.

Despite the small number of cases, and the already described difficulties, the data supplied by this study are relevant as the results provide novel information in the context of $\mathrm{CD}$ epidemiological information regarding Brazilian individuals, and reinforces information from other countries, offering important new information that may contribute to a better understanding of the disease and its relation to MAP.

Although statistically non-significant, probably due to the small sample size, several factors play an important role in the identification of agents in the intestinal biopsies of patients with IBD and other diseases, for example performing abdominal surgery. Among the cases, a family history of bowel disease was always diagnosed as CD. These results support other studies reporting that MAP DNA 
is generally found among patients with CD 7. Infected patients may develop intestinal problems associated with a genetic propensity, including mutations in the Nod 2, which is gene associated with the processing of modified bacterial products $[9,27]$. Besides, individuals infected with the agent may contaminate their families through direct contact or fomites of contamination.

The data show the habits of the patients in relation to the consumption of milk and other dairy products. This is relevant to the study, since sick bovine carriers eliminate the agent through the milk as well as the feces. It seems that $76.4 \%$ of the total population consumes dairy products at least once per week, which corresponds to $100 \%$ of the controls and $75 \%$ of the cases. The high frequency of consumption of these products increases the risk of contamination of these individuals. As for the types of dairy products consumed, $45.2 \%$ of the study participants in the study said that they consume both pasteurized and informally marketed or unpasteurized products, while $43.9 \%$ consume only pasteurized products. The comparison between cases and controls revealed different ratios, i.e. $87.5 \%$ of cases consume pasteurized and unpasteurized milk, while only $50.4 \%$ of controls consume these products.

Participants were asked whether they process the informally marketed products prior to consumption; $60.8 \%$ said they do not consume these products, $11.5 \%$ said they consume it raw and $25.6 \%$ said they boil it. The cases consumed dairy products, especially raw milk, that increase the risk of MAP contamination. It is important to emphasize that, among the cases, $62.5 \%$ of subjects consumed raw milk, whereas only $10.8 \%$ of controls did so, as described in Table 4. According to Nielsen, et al. (2008) even for the calves themselves, the intake of colostrum or milk, depending on the management of colostrum, may represent a risk factor for MAP infection $[29,30]$.

The participants were also asked about where they had purchased milk products, since buying from small establishments, street vendors or directly from farms are usually associated with uninspected products, which are more vulnerable to pathogen contamination. It was found that $44.5 \%$ of the participants had acquired their products in the supermarket, which corresponds to $12.5 \%$ of the cases and $46.8 \%$ of controls. Another $6.08 \%$ had bought the products in bakeries, i.e. $12.5 \%$ of cases and $5.8 \%$ of controls, and another $4.7 \%$ had bought their dairy products in grocery stores, i.e. $12.5 \%$ of cases and $4.3 \%$ of controls (Table 4 ).

Most (72.2\%) participants had no family history of intestinal disease. The profile was similar for controls and differed for cases. Furthermore, these individuals were diagnosed with other noninflammatory bowel diseases (12.1\%) followed by RCU $(8.1 \%)$ and $\mathrm{CD}$ (3.3). All the cases were diagnosed with $\mathrm{CD}$, as can be seen in the Table 4.

The bivariate analysis considered only variables that could be categorized into exposed and unexposed. The results are shown in Tables 1 to 4 .

Despite the differences displayed in the univariate analysis, which suggests some risk factors, only the variables intake of milk and informal derivatives showed an association $(\mathrm{OD}=13.39, \mathrm{CI}=1.57$ to $298 \mathrm{p}<0.01)$, while a history of intestinal disease among family members $(\mathrm{OD}=8.42, \mathrm{CI}=1.44$ to $63.50 ; \mathrm{p}<0.01)$ showed statistical relevance.

\section{Conclusion}

The consumption of informally marketed milk and a previous history of intestinal diseases among family members can be considered risk factors for the presence of MAP DNA in intestinal biopsies. Also, for the studied population, the characterization suggests some other possible risk factors, including undergoing surgery. These data reinforce the available data in the literature regarding the risk factors for $\mathrm{CD}$ in other countries.

\section{Acknowledgment}

The authors acknowledge the funding agencies CAPES (Coordenação de Aperfeiçoamento de Pessoal de Nível Superior, $\mathrm{CNPq}$ (Conselho Nacional de Desenvolvimento Científico e Tecnológico) and FAPEMIG (Fundação de Amparo à Pesquisa do Estado de Minas Gerais) for the financial support. Moreira, M. A. S. is supported by CNPq.

\section{References}

1. Chiodini RJ, Van Kruiningen HJ, Merkal RS. Ruminant Paratuberculosis (Johne's Disease): The Current Status And Future Prospects. Cornell Veterinarian, 1984. 74: 218-262

2. Sweeney RW. Transmission of paratuberculosis. Vet Clin North Am Food Anim Pract. 1996; 12: 305-312.

3. Sands BE. Crohn's Disease. Sleisenger And Fordtran's Gastrointestinal And Liver Disease. Philadelphia: Saunders Elsevier. 2006; 2459-2498.

4. Robertson RE, Cerf O, Condron RJ, Donaghy JA, Heggum C, Jordan K. Review of the controversy over whether or not Mycobacterium avium subsp. paratuberculosis poses a food safety risk with pasteurised dairy products. International Dairy Journal.2017

5. Naser SA, Schwartz D, Shafran I. Isolation Of Mycobacterium avium Subsp Paratuberculosis From Breast Milk Of Crohn's Disease Patients. AmJ Gastroenterol. 2000. 95: 1094-1095.

6. Carvalho IA, Schwarz DGG, Pietralonga PAG, Faria ACS, Braga IFE, et al Presence Of Mycobacterium avium Subsp. Paratuberculosis (Map). Brazilian Patients With Inflammatory Bowel Diseases And Controls. São Paulo Med J. 2015; 134: 13-19.

7. Prantera C, Bothamley G, Levenstein S, Mangiarotti R, Argentieri R. Crohn's disease and mycobacteria: two cases of Crohn's disease with high anti-mycobacterial antibody levels cured by dapsone therapy. Biomed Pharmacother. 1989; 43: 295-299.

8. Nacy C, Buckley M. Mycobacterium avium Paratuberculosis:Infrequent Human Pathogen Or Public Health Threat? American Acadamy of Microbiology. 2008; 1-37.

9. Fiocchi C. Etiopatogênese Da Doença Inflamatória Intestinal. Im: Cardozo Ws, Sobrado Cw. Doença Inflamatória Intestinal. Barueri: Manole; 2012.

10. Mishina D, Katsel P, Brown ST, Gilberts EC, Greenstein RJ. On the etiology of Crohn disease. Proc Natl Acad Sci U S A. 1996; 93: 9816-9820.

11. Sung N, Collins MT. Thermal tolerance of Mycobacterium paratuberculosis. Appl Environ Microbiol. 1998; 64: 999-1005.

12. Whan LB, Gran IR. Bactericidal Effect Of Chlorine On Mycobacterium Paratuberculosis In Drinking Water. Letters In Applied Microbiology. 2001; 33: 227-231.

13. Beumer A, King D, Donohue M, Mistry, J, Covert T, Pfaller S. Detection of Mycobacterium avium subsp. paratuberculosis in drinking water and biofilms by quantitative PCR. Appl Environ Microbiol. 2010, 76: 7367-7370.

14. Carvalho IA, Pietralonga PAG, Schwarz DGG, Faria ACS, Moreira MAS Short Communication: Recovery Of Viable Mycobacterium avium Subspecies 
Paratuberculosis From Retail Pasteurized Whole Milk In Brazil. J. Dairy Sci. 2012. 95: 6946-6948

15. Uzoigwe, JC, Khaitsa ML, Gibbs, PS. Epidemiological evidence for Mycobacterium avium subspecies paratuberculosis as a cause of Crohn's disease. Epidemiology and Infection. 2007; 1057-1068

16. Scanu AM, Bull TJ, Cannas S, Sanderson JD, Sechi LA, Dettori G, et al Mycobacterium avium subspecies paratuberculosis infection in cases of irritable bowel syndrome and comparison with Crohn's disease and Johne's disease: common neural and immune pathogenicities. Journal of clinical microbiology, 2007. 45: 3883-3890.

17. Zamani S, Zali MR, Aghdaei HA, Sechi LA, Niegowska M, Caggiu E, et al Mycobacterium avium subsp. paratuberculosis and associated risk factors for inflammatory bowel disease in Iranian patients. Gut Pathog. 2017; 9: 1.

18. Abubakar I, Myhill DJ, Hart AR, Lake IR, Harvey I, Rhodes JM, et al. A casecontrol study of drinking water and dairy products in Crohn's disease-further investigation of the possible role of Mycobacterium avium paratuberculosis Am J Epidemiol. 2007; 165: 776-783.

19. Dow CT. Paratuberculosis and Type I diabetes: is this the trigger? Med Hypotheses. 2006; 67: 782-785.

20. Pinna A, Masala S, Blasetti F, Maiore I, Cossu D, Paccagnini D, et al. Detection of serum antibodies cross-reacting with Mycobacterium avium subspecies paratuberculosis and beta-cell antigen zinc transporter 8 homologous peptides in patients with high-risk proliferative diabetic retinopathy. PLoS One. 2014; 9: e107802.

21. CDC- Centers For Diseases Control. Available in .

22. Timms VJ, Daskalopoulos G, Mitchell HM, Neilan BA. The Association of Mycobacterium avium subsp. paratuberculosis with Inflammatory Bowel Disease. PLoS One. 2016; 11: e0148731.
23. Berquó LS, Barros AJ, Lima RC, Bertoldi AD. Use of antimicrobial drugs in an urban population. Rev Saude Publica. 2004; 38: 239-246.

24. Grant IR, Ball HE, Rowe MT. Incidence Of Mycobacterium Paratuberculosis In Bulk Raw And Commercially Pasteurized Cows' Milk From Approved Dairy Processing Establishments In The United Kingdom. Appl Environ Microbiol. 2002; 68: 2428-2435.

25. Faria ACS, Schwarz DGG, Carvalho IA, Rocha BB, Castro KDC, Silva MR, et al. Short Communication: Viable Mycobacterium avium Subspecies Paratuberculosis In Retail Artisanal Coalho Cheese From Northeastern Brazil. J Dairy Sci. 2014. 97: 4111-4114.

26. Pierce ES. Possible Transmission Of Mycobacterium avium Subspecies Paratuberculosis Through Potable Water: Lessons From An Urban Cluster Of Crohn's Disease.Gut Pathogens. 2009; 1: 1-17.

27. Lamont EA, Bannantine JP, Armién A, Ariyakumar DS, Sreevatsan S Identification And Charac Terization Of A Spore-Like Morphotype In Chronically Starved Mycobacterium avium Subsp. paratuberculosis Cultures. Plos One. 2012; 7: E30648.

28. Leite AZA. Epidemiologia Da Doença Inflamatória Intestinal. Em: Cardozo Ws, Sobrado Cw, Doença Inflamatória Intestinal. Barueri: Manole; 2012.

29. Nielsen SS, Bjerre $\mathrm{H}$, Toft N. Colostrum and milk as risk factors for infection with Mycobacterium avium subspecies paratuberculosis in dairy cattle. J Dairy Sci. 2008; 91: 4610-4615

30. Grant IR, Hitchings El, Mccartney A, Ferguson FE, Rowe MT. Effect Of Commercial-Scale High-Temperature, Short-Time Pasteurization On The Viability Of Mycobacterium Paratuberculosis In Naturally Infected Cows' Milk. Appl Environ Microbiol. 2002; 68: 602-607.
Austin J Gastroenterol - Volume 4 Issue 2 - 2017

ISSN : 2381-9219 | www.austinpublishing group.com

Moreira et al. (c) All rights are reserved
Citation: Espeschit IF, Carvalho IA, Oliveira JF, Souza MCC, Valêncio A, Ferrari MLA, et al. Risk Factors for the Presence of Mycobacterium avium spp. paratuberculosis in Human Intestinal Biopsies in Brazil. Austin J Gastroenterol. 2017; 4(2): 1083. 